\title{
"Act on Threes" Paradigm for Treatment Intensification of Type 2 Diabetes in Managed Care: Results of a Randomized Controlled Study with an Educational Intervention Targeting Improved Glycemic Control
}

\author{
Nella Bieszk, PharmD; Shannon L. Reynolds, MSPH; Wenhui Wei, PhD, MS, MBA; Cralen Davis, MS; \\ Pravin Kamble, RPh, MS, PhD; and Claudia Uribe, MD, MHA, PhD
}

\begin{abstract}
BACKGROUND: Clinical inertia, which has been defined as the recognition of a problem with a patient's management but failing to act, is a concern in type 2 diabetes (T2D) because it places the patient at risk of diabetesrelated complications. Despite managed care organizations making significant investment in this area, little is known about the impact of educational programs aimed at aligning patients and their physicians with diabetes guidelines and thus overcoming clinical inertia.

OBJECTIVE: To assess the impact of an educational intervention specifically designed to align patients and their physicians with 2012 American Diabetes Association (ADA) guidelines on glycated hemoglobin (A1c) testing frequency and insulin initiation.
\end{abstract}

METHODS: The "Act on Threes" educational intervention was a 12-month, randomized controlled prospective study that included Medicare Advantage patients aged 18-85 years with T2D, who received $\geq 3$ oral antidiabetes drugs (OADs) and/or had A1c not at goal and/or had no recent A1c evaluation over 12 months, as identified through the analysis of administrative claims data (May 1, 2011-April 30, 2013) from the Humana database. Identified patients were randomized 3:1 to receive the Act on Threes educational intervention in conjunction with standard care (intervention group) or standard care alone (control group). For the educational intervention, patients and physicians were simultaneously mailed general and targeted information aimed at aligning them to 3 vital aspects of A1c control: timely measurement of A1c every 3 months; timely treatment intensification to meet A1c goals with treatment intensification every 3 months if A1c is not at goal; and insulin initiation when appropriate, including patients receiving $\geq 3$ OADs with A1c not at goal. Control patients were only enrolled if the treating physician was not involved in the care of any patients in the intervention group. The primary outcome measures were A1c testing frequency based on the ADA standard for compliance of $\geq 2$ tests per year and insulin initiation in the 12-month postintervention period. A1c levels were evaluated for the subgroup of patients with available A1c measurements in the pre- and postintervention periods. Descriptive statistics were used to analyze differences between the intervention and control groups. Multiple logistic regression analysis was used to identify determinants of insulin initiation in the full study cohort.

RESULTS: 6,243 patients (mean age 70 years; $43.5 \%$ female) were identified: 4,555 were randomized to the intervention group and 1,688 to the control group. The percentage of patients with $\geq 2$ A1c tests per year was not significantly different postintervention for patients in the intervention and control groups ( $47.7 \%$ vs. $46.8 \%$, respectively; $P=0.995)$. Intriguingly, the frequency of A1c testing increased significantly from pre- to postintervention in the intervention and control groups. Change in A1c level from pre- to postintervention was also similar for the 2 groups $(P=0.240)$. A similar percentage of patients in the intervention and control groups initiated insulin during the postintervention period $(6.3 \%$ vs. $7.6 \%$, respectively; $P=0.059)$.
CONCLUSIONS: This randomized controlled study demonstrated that, compared with standard care, the Act on Threes educational intervention combined with standard care did not result in any significant differences in the frequency of A1c testing or in the initiation of insulin in patients with T2D. These findings are in contrast to uncontrolled comparative studies showing significant improvements in outcomes postintervention and reinforce the importance of study design in evaluating the effectiveness of educational programs.

J Manag Care Spec Pharm. 2016;22(9):1028-38

Copyright $\odot 2016$, Academy of Managed Care Pharmacy. All rights reserved.

\section{What is already known about this subject}

A low proportion of patients with type 2 diabetes (T2D) experience care that aligns with the American Diabetes Association (ADA) position statement regarding glycated hemoglobin (Alc) testing frequency; the average patient has an Alc level $>7.0 \%$ for approximately 10 years and $>8.0 \%$ for approximately 5 years before insulin initiation.

Positive effects on diabetes-related outcomes have been reported from studies that evaluated interventions aimed at improving diabetes management delivered in the form of educational mail-outs that targeted patients and physicians.

The majority of intervention studies used a pre- versus postintervention comparison without the inclusion of control groups.

\section{What this study adds}

This randomized controlled study showed that, compared with standard care, an educational intervention program such as "Act on Threes" did not result in a significant difference in treatment intensification with insulin and glycemic control in high-risk patients with $\mathrm{T} 2 \mathrm{D}$, despite an increase in Alc testing frequency in both cohorts during the study period.

An intervention that would increase awareness among physicians and patients of the long-term outcomes of an Alc level $>8.0 \%$ and delayed insulin initiation may be better able to help overcome clinical inertia and promote insulin initiation in alignment with the current ADA recommendations. 
"Act on Threes" Paradigm for Treatment Intensification of Type 2 Diabetes in Managed Care:

Results of a Randomized Controlled Study with an Educational Intervention Targeting Improved Glycemic Control

\section{What this study adds (continued)}

The lack of effect of the Act on Threes educational intervention challenges the validity of other studies of educational interventions that have shown significant changes in diabetes-related outcomes based on a pre- to postintervention design without the use of appropriate control groups.

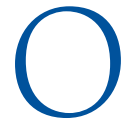
ptimal glycemic control is critical in order to reduce the risk of diabetes-related morbidity and complications, as well as to reduce medical costs and health care utilization. However, optimal management of patients with type 2 diabetes (T2D) is a significant clinical challenge for any general practitioner or specialist physician. ${ }^{1,2}$ Despite extensive research demonstrating the clinical benefits of glycemic control — and, notably, the benefits of early insulin initiation ${ }^{3,4}$ - at least $60 \%$ of U.S. patients with T2D enrolled in commercial or Medicaid health maintenance organization plans who are appropriate candidates for stringent glycated hemoglobin (Alc) goals fail to attain the American Diabetes Association (ADA) recommended Alc goal of $7.0 \%$ or less. ${ }^{1,5,6}$ Even considering the recent emphasis of the ADA on patient-centered care and the appropriateness of less stringent Alc targets such as in older patients with comorbidities, an estimated $54.5 \%$ of Medicaid patients, $41.1 \%$ of patients on a commercial insurance plan, and $34.5 \%$ of Medicare patients fail to achieve an Alc goal of $8.0 \%$ or less. ${ }^{5,6}$

For patients with good glycemic control and who meet treatment goals, Alc testing is recommended twice a year, with quarterly testing for those not at goal and whose therapy has changed. ${ }^{7}$ Yet, in a large U.S. cohort of adult patients with T2D, just $7 \%$ were adherent for 1 year to ADA guidelines for Alc testing frequency, and therapy was modified in accordance with guidelines in just 39\%. ${ }^{8}$ Another study indicated that from T2D diagnosis, the average patient spent approximately 10 years with an Alc level $>7.0 \%$ and approximately 5 years with an Alc level $>8.0 \%$ before initiating insulin. ${ }^{9}$

Patient and physician concerns, particularly in relation to insulin initiation, contribute to delays in treatment intensification in patients with $\mathrm{T} 2 \mathrm{D}^{10}$; this clinical inertia may put patients at risk of diabetes-related complications., ${ }^{1,2}$ Managed care organizations and the pharmaceutical industry invest heavily in physician- and patient-targeted educational outreach programs to overcome clinical inertia and patients' reluctance to initiate insulin, but little is currently known about the impact of such programs. Positive results from studies that have evaluated preversus postintervention outcomes of educational initiatives that targeted patients and physicians via mail-outs have encouraged similar interventions in managed care. However, these studies did not employ a randomized controlled study design to evaluate the impact on outcomes in those exposed versus those not exposed to the interventions. ${ }^{11,12}$

The objective of the "Act on Threes" educational intervention was to align patients with T2D and their physicians with the 2012 ADA position statement on T2D management ${ }^{5}$ and to assess 3 vital aspects of Alc control: the timely measurement of Alc levels every 3 months; timely treatment intensification to meet Alc goals, with treatment intensified every 3 months if Alc is not at goal; and insulin initiation when appropriate, including in patients already receiving $\geq 3$ oral antidiabetes drugs (OADs) with Alc not at goal. Unlike previous studies, the Act on Threes intervention used a rigorous, randomized design with the objective of evaluating the impact of the educational intervention on Alc testing frequency and insulin initiation in patients with T2D who had not received Alc testing or had suboptimal control of their Alc ( $\geq 8.0 \%$ ) according to the 2012 ADA position statement. ${ }^{5}$ The secondary objective was to identify factors that predict insulin initiation in patients with T2D enrolled in the study.

\section{Methods}

\section{Study Design}

This was a 12-month, prospective, randomized, and interventional study of adult patients with T2D that evaluated the effects of the Act on Threes educational intervention on Alc testing frequency and insulin initiation through the analysis of administrative claims data from the Humana database. Humana is a for-profit health insurance company with more than 13 million U.S.-based customers. Following retrospective identification of patients with high-risk status using medical, pharmacy, laboratory, and enrollment indices of Alc screening frequency; number of noninsulin antihyperglycemic medications; and/or Alc test results as per ADA criteria for Alc testing frequency and antidiabetic treatment modifications ${ }^{8}$ (identification period May 1, 2011-April 30, 2013), patients were randomized 3:1 to receive either the Act on Threes educational intervention in conjunction with standard care (intervention group) or standard care alone (control group; Figure 1). Controls were eligible only if the treating physician was a different physician from that of any intervention patient. The full study period included a 12-month pre-intervention (baseline) period and a 12-month postintervention (follow-up) period, with the index date being the date of the most recent diagnosis of T2D during the identification period.

\section{Patients and Physicians}

High-risk Medicare Advantage with prescription drug coverage (MAPD) members were eligible if they were aged 18-85 years with $\geq 1$ inpatient or 2 physician visits dated $\geq 30$ days apart with a primary or secondary diagnosis of T2D using International Classification of Diseases, Ninth Revision, Clinical Modification (ICD-9-CM) codes 250.x0 or 250.x2. Patients were 
"Act on Threes" Paradigm for Treatment Intensification of Type 2 Diabetes in Managed Care:

Results of a Randomized Controlled Study with an Educational Intervention Targeting Improved Glycemic Control

FIGURE 1 Patient Selection and Cohort Attrition in Humana MAPD Dataset

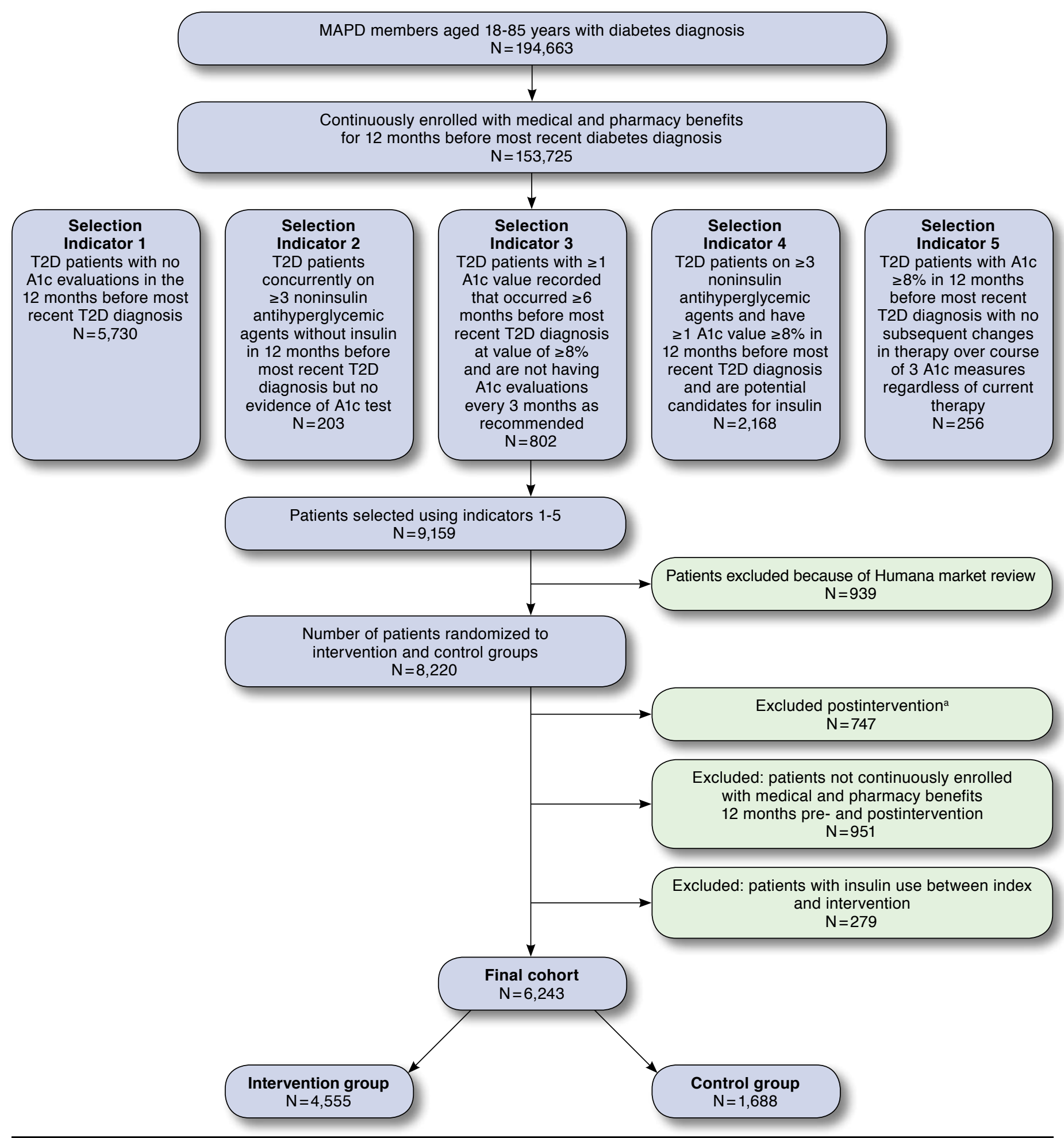

aneligible or unreachable based on provider feedback and returned mailings.

Alc = glycated hemoglobin; MAPD = Medicare Advantage Plan D; T2D = type 2 diabetes. 
"Act on Threes" Paradigm for Treatment Intensification of Type 2 Diabetes in Managed Care:

Results of a Randomized Controlled Study with an Educational Intervention Targeting Improved Glycemic Control

TABLE 1 Patient Demographic and Baseline Clinical Characteristics

\begin{tabular}{|c|c|c|c|c|}
\hline Characteristic & $\begin{array}{c}\text { Intervention Patients } \\
\qquad N=4,555\end{array}$ & $\begin{array}{c}\text { Control Patients } \\
N=1,688\end{array}$ & $P$ Value & $\begin{array}{l}\text { Standardized } \\
\text { Difference }\end{array}$ \\
\hline Age, years, mean [SD] & $70.3 \quad[8.3]$ & $70.7 \quad[8.2]$ & 0.062 & 0.053 \\
\hline Female, n (\%) & $2,002 \quad(44.0)$ & $716 \quad(42.4)$ & 0.277 & 0.031 \\
\hline Race, n (\%) & & & 0.826 & \\
\hline White & $3,580 \quad(78.6)$ & $1,325 \quad(78.5)$ & & 0.002 \\
\hline Black & $717 \quad(15.7)$ & $275 \quad(16.3)$ & & 0.015 \\
\hline Hispanic & $107 \quad(2.4)$ & $34 \quad(2.0)$ & & 0.023 \\
\hline Other & $151 \quad(3.3)$ & $54 \quad(3.2)$ & & 0.007 \\
\hline Low-income subsidy, n (\%) & $893 \quad(19.6)$ & $334 \quad(19.8)$ & 0.872 & 0.005 \\
\hline MAPD plan type, n (\%) & & & 0.790 & \\
\hline Standard (HMO) & $2,084 \quad(45.8)$ & $764 \quad(45.3)$ & & 0.010 \\
\hline Enhanced (PPO) & $1,948 \quad(42.8)$ & $737 \quad(43.7)$ & & 0.018 \\
\hline Complete (FFS) & $523 \quad(11.5)$ & $187 \quad(11.1)$ & & 0.013 \\
\hline Alc, mean [SD], \% & $8.66 \quad[1.5]$ & $8.53 \quad[1.4]$ & 0.043 & 0.098 \\
\hline Alc category, n (\%) & & & 0.537 & \\
\hline$<6 \%$ & $(0.5)$ & $5 \quad(0.8)$ & & 0.020 \\
\hline $6.0 \%-6.9 \%$ & $128 \quad(7.6)$ & $53 \quad(8.8)$ & & 0.019 \\
\hline $7.0 \%-7.9 \%$ & $353 \quad(21.1)$ & $136 \quad(22.7)$ & & 0.011 \\
\hline $8.0 \%-8.9 \%$ & $652(38.9)$ & $232(38.7)$ & & 0.016 \\
\hline $9.0 \%$ & $534 \quad(31.9)$ & $174 \quad(29.0)$ & & 0.045 \\
\hline Deyo-Charlson Comorbidity Index, mean [SD] & $2.63 \quad[2.1]$ & $2.57 \quad[2.0]$ & 0.237 & 0.034 \\
\hline \multicolumn{5}{|l|}{ Comorbidities, n (\%) } \\
\hline Hypertension & $3,521 \quad(77.3)$ & $1,298 \quad(76.9)$ & 0.736 & 0.010 \\
\hline Dyslipidemia & $2,454 \quad(53.9)$ & $896 \quad(53.1)$ & 0.576 & 0.016 \\
\hline Neuropathy & $996 \quad(21.9)$ & $334 \quad(19.8)$ & 0.075 & 0.051 \\
\hline Depression & $334 \quad(7.3)$ & $114 \quad(6.8)$ & 0.431 & 0.023 \\
\hline Amputation/ulceration & $254 \quad(5.6)$ & $83 \quad(4.9)$ & 0.306 & 0.030 \\
\hline Retinopathy & $250 \quad(5.5)$ & $86 \quad(5.1)$ & 0.540 & 0.018 \\
\hline Hypoglycemia & (5.4) & $90 \quad(5.3)$ & 0.942 & 0.002 \\
\hline Obesity & (5.3) & $71 \quad(4.2)$ & 0.070 & 0.053 \\
\hline Nephropathy & $(2.4)$ & $40 \quad(2.4)$ & 0.996 & 0.000 \\
\hline \multicolumn{5}{|l|}{ Physician visit, n (\%) } \\
\hline General practitioner & $4,017 \quad(88.2)$ & $1,483 \quad(87.9)$ & 0.718 & 0.010 \\
\hline Specialist $^{\mathrm{a}}$ & $554 \quad(12.2)$ & $212 \quad(12.6)$ & 0.671 & 0.012 \\
\hline Endocrinologist & $199 \quad(4.4)$ & $\begin{array}{ll}65 & (3.9) \\
\end{array}$ & 0.366 & 0.026 \\
\hline
\end{tabular}

aspecialist includes endocrinologist, geriatrician, and nephrologist.

FFS = fee for service; $H M O=$ health maintenance organization; $M A P D=$ Medicare Advantage Plan $D ; P P O=$ preferred provider organization; $S D=$ standard deviation .

required to have continuous enrollment in the MAPD plan with medical and pharmacy coverage for $\geq 12$ months before (baseline) the most recent T2D diagnosis (index date) and current enrollment at the time of identification. Additionally, patients were required to meet 1 of the following high-risk selection indicators: (a) have no Alc evaluations in the 12 months before the index date; (b) concurrent use of $\geq 3$ noninsulin antihyperglycemic agents without insulin at any time in the 12 month period before the index date, but without evidence of a medical claim for an Alc test; (c) at least 1 Alc value $\geq 8.0 \%$ that occurred $\geq 6$ months before the index date, without any Alc evaluations within the previous 6 months; (d) taking $\geq 3$ noninsulin antihyperglycemic agents and having $\geq 1 \mathrm{Alc}$ value $\geq 8.0 \%$ in the 12 months before the index date; (e) at least
1 Alc value $\geq 8.0 \%$ in the 12 months before the index date with no subsequent change in therapy over the course of $3 \mathrm{Alc}$ measures $\geq 8.0 \%$ regardless of current therapy. Patients with a prescription claim for insulin in the pre-intervention period were excluded. Patient selection was fully anonymized and compliant with Health Insurance Portability and Accountability Act regulations. Physicians targeted for the intervention were those involved in the treatment of the selected patients.

\section{Act on Threes Intervention}

The Act on Threes educational intervention had a 2-pronged approach that incorporated general and targeted T2D educational materials and cover letters, which were simultaneously mailed to patients and their treating physicians twice (see 
"Act on Threes" Paradigm for Treatment Intensification of Type 2 Diabetes in Managed Care: Results of a Randomized Controlled Study with an Educational Intervention Targeting Improved Glycemic Control

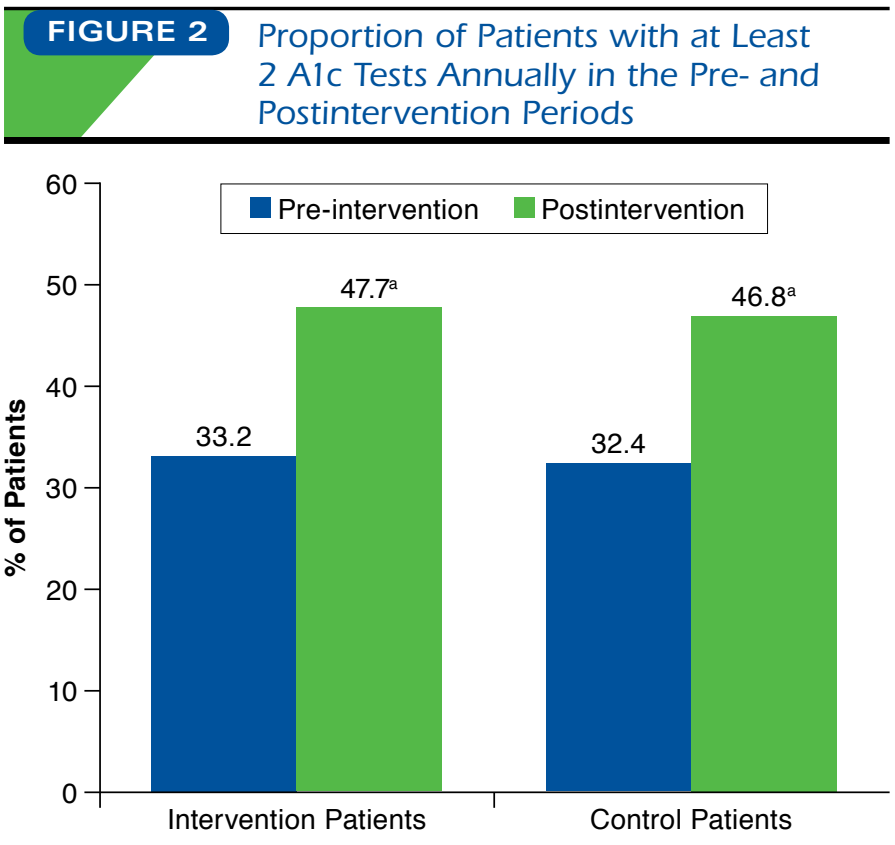

aP $<0.001$ for the pre-versus postintervention comparison. Alc $=$ glycated hemoglobin.

Appendices A-D, available in online article). The educational materials were concise and used language at a level considered appropriate for patient and physician groups. The materials were developed in association with Humana's in-house clinical task force and communications team and were consistent with ADA clinical guideline recommendations for Alc testing frequency and treatment modification in patients with T2D. General T2D educational materials included patient and physician brochures (Appendices B and D, available in online article). A simple brochure encouraged patients to see their doctors for an Alc test every 3 months until Alc is at goal, then at least every 6 months to maintain goal Alc; talk to their doctors about their medications every 3 months if Alc is not at goal; and talk to their doctors about using insulin if they are on $\geq 3$ diabetes medications, and Alc is not at goal. Another brochure was sent to physicians encouraging them to measure their patients' Alc every 3 months; intensify treatment every 3 months for patients not at goal Alc; and consider starting insulin for patients using $\geq 3$ noninsulin antihyperglycemic drugs. Targeted educational materials were sent to physicians in the form of patient-specific profiles, outlining the reason why the patient was classified as high risk, together with relevant diabetes-related information such as comorbidities, hospitalizations, medication use, and laboratory Alc results (Appendix $\mathrm{E}$, available in online article). The profiles were presented with 1 patient per page so the data could be easily incorporated into the patient's chart. Follow-up letters were sent to physicians and patients 3 months after the initial mailing. The control group received standard care and did not receive any messaging as part of the study.

\section{Outcome Measures}

The primary outcome measures were Alc testing frequency, as recorded in the medical claims, and based on the ADA standard for compliance of $\geq 2$ tests per year and insulin initiation in the postintervention period, as recorded in the pharmacy claims. Alc testing frequency was measured in the entire study cohort, which was composed of patients remaining on the same treatment regimen and patients who changed treatment regimen (including those who initiated insulin therapy). Alc levels were examined for the subgroup of patients with available Alc measurements in the pre- and postintervention period.

Act on Threes campaign-related measures during the postintervention period were secondary outcomes and included the following: the number of T2D patients who had $\geq 1 \mathrm{Alc}$ measure; the number of patients who had Alc measures every 3 months; the number of patients who initiated insulin; the number of patients who switched to insulin; and the number of patients with any change in treatment. Other secondary outcome measures were the frequency and proportion of patients who discontinued any OAD used in the 30 days before switching to insulin, with discontinuation defined as a 90-day gap in receipt of medication and including refills, and diabetes therapy intensification, defined as the number of class-level OADs added during the postintervention period in addition to those received in the pre-intervention period. Hypoglycemic events in any setting were identified by ICD-9-CM codes 250.8, 251.0, 251.1, and 251.2.

\section{Statistical Analyses}

Descriptive statistics were used to analyze differences in demographic and clinical characteristics between the intervention and control groups. Differences in the proportions of patients with $\geq 2 \mathrm{Alc}$ tests in the pre- and postintervention periods were evaluated for each group using the McNemar test; the Student's t-test was used to evaluate between-group differences. Bivariate comparisons of outcome measures in the intervention and control groups were made using $\mathrm{X}^{2}$ tests to evaluate for statistical significance of differences in proportions of patients. Multiple logistic regression analysis of the entire study cohort was used to assess predictors of insulin initiation in the post hoc analysis. All analyses of data were conducted using SAS software, version 9.1 (SAS Institute, Cary, NC).

The a priori alpha level for all inferential analyses was set at 0.05 , and all statistical tests were 2-tailed. For the secondary objective of examining predictors of insulin initiation, an analysis of the data was conducted to evaluate insulin initiation in patients with T2D who had available Alc measures in the pre- and postintervention periods. During the 12-month postintervention period, insulin initiation was examined in 
"Act on Threes" Paradigm for Treatment Intensification of Type 2 Diabetes in Managed Care:

Results of a Randomized Controlled Study with an Educational Intervention Targeting Improved Glycemic Control

\section{FIGURE 3 Act on Threes Campaign-Related Measures Among Patients Stratified by} High-Risk Selection Indicators 1 to 5

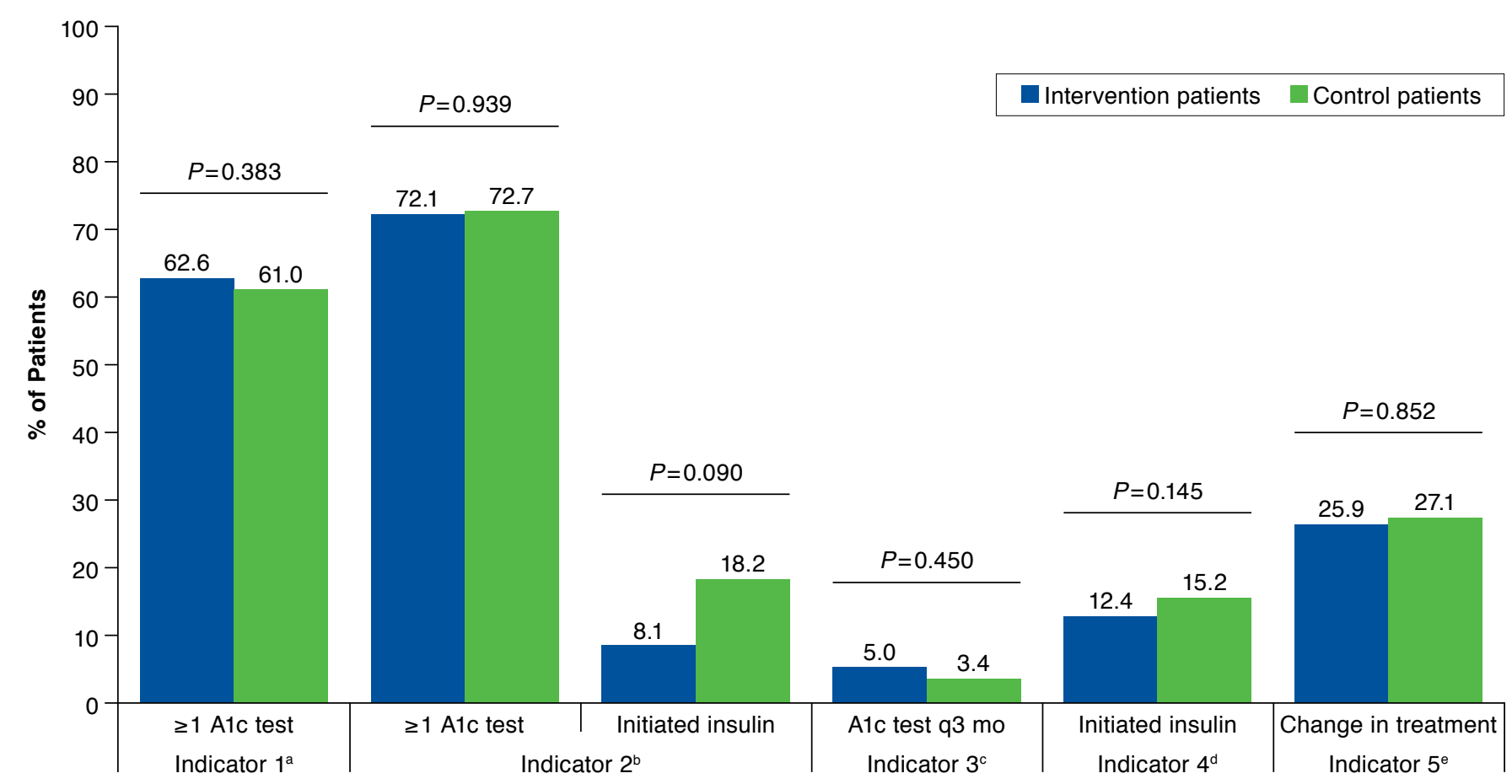

High-Risk Selection Indicators

aT2D patients who have had no Alc evaluations in the 12 months before the most recent T2D diagnosis.

${ }^{b} \mathrm{~T} 2 \mathrm{D}$ patients concurrently on $\geq 3$ noninsulin antihyperglycemic agents without insulin at any time in the 12-month period before the most recent T2D diagnosis, but no evidence in the medical claims that an A1c test was performed.

${ }^{c} T 2 D$ patients with $\geq 1$ Alc value recorded that occurred 6 months or more before the most recent T2D diagnosis at a value of $\geq 8.0 \%$ and with no A1c evaluations in the 6 months before the most recent T2D diagnosis.

${ }^{d} \mathrm{~T} 2 \mathrm{D}$ patients who are on $\geq 3$ noninsulin antihyperglycemic agents and with $\geq 1$ Alc value $\geq 8.0 \%$ in the 12 months before the most recent T2D diagnosis and therefore represent potential candidates for insulin.

'T2D patients with an Alc value of $8.0 \%$ in the 12 months before the most recent T2D diagnosis with no subsequent change in therapy over the course of 3 Alc measures, regardless of current therapy.

Alc = glycated hemoglobin; T2D = type 2 diabetes; 93 mo=every 3 months.

the entire cohort using pharmacy claims, and its determinants were identified from patients' pre-intervention demographic and clinical characteristics.

\section{Results}

\section{Patient Demographics and Baseline Characteristics}

Patient attrition is summarized in Figure 1. A total of 6,243 patients with a mean age of 70 years $(43.5 \%$ female) were identified in this study; 4,555 patients were randomized to the intervention group and 1,688 patients to the control group. Patients in the intervention group had a significantly higher mean Alc level at baseline compared with the control group ( $8.66 \%$ vs. $8.53 \%$, respectively; $P=0.043$ ). Otherwise, patient demographics and baseline characteristics were similar for the 2 groups (Table 1 ).

\section{Primary and Secondary Outcomes}

The percentage of patients with $\geq 2$ Alc tests per year was significantly higher postintervention compared with preintervention in the intervention and control groups $(P<0.001$; Figure 2). However, when the pre- to postintervention change was compared for intervention and control patients, there was no significant difference between the groups in the proportion of patients who received $\geq 2$ Alc tests $(P=0.995)$. For patients with pre- and postintervention Alc measurements (intervention group: $n=1,503$; control group: $n=539$ ), Alc levels were similar for the intervention (mean [SD]: pre-intervention, 7.94\% [1.47] vs. postintervention, $7.98 \%$ [1.45]; $P=0.540)$ and control groups (mean [SD]: pre-intervention, 7.98\% [1.57] vs. postintervention, $7.94 \%$ [1.52]; $P=0.630$ ). There was also 
"Act on Threes" Paradigm for Treatment Intensification of Type 2 Diabetes in Managed Care: Results of a Randomized Controlled Study with an Educational Intervention Targeting Improved Glycemic Control

\begin{tabular}{|c|c|c|}
\hline \multicolumn{3}{|c|}{$\begin{array}{l}\text { Proportion of Patients with } \\
\text { Intensification of Diabetes Therapy } \\
\text { Stratified According to Number of } \\
\text { Class-Level OADs Added During } \\
\text { Postlntervention Period }\end{array}$} \\
\hline Outcome & $\begin{array}{c}\text { Intervention } \\
\text { Patients } \\
\mathrm{N}=4,555\end{array}$ & $\begin{array}{c}\text { Control } \\
\text { Patients } \\
\mathrm{N}=1,688\end{array}$ \\
\hline $\begin{array}{l}\text { Patients on } 1 \text { OAD medication during } \\
\text { pre-intervention period, } \mathrm{n}(\%)\end{array}$ & $1,194 \quad(26.2)$ & $445 \quad(26.4)$ \\
\hline 0 & 1,035 & $383(86.1)$ \\
\hline 1 & 139 (11.6) & 53 (11.9) \\
\hline $2+$ & $20 \quad(1.7)$ & $9 \quad(2.0)$ \\
\hline $\begin{array}{l}\text { Patients on } 2 \text { OAD medications during } \\
\text { pre-intervention period, } \mathrm{n}(\%)\end{array}$ & $1,008 \quad(22.1)$ & $371(22.0)$ \\
\hline 0 & $894(88.7)$ & $329(88.7)$ \\
\hline 1 & $111(11.0)$ & $40 \quad(10.8)$ \\
\hline $2+$ & $3 \quad(0.3)$ & $2 \quad(0.5)$ \\
\hline $\begin{array}{l}\text { Patients on } \geq 3 \text { OAD medications } \\
\text { during pre-intervention period, } n(\%)\end{array}$ & $1,045 \quad(22.9)$ & $380(22.5)$ \\
\hline 0 & $966(92.4)$ & 352 (92.6) \\
\hline 1 & $77 \quad(7.4)$ & $27 \quad(7.1)$ \\
\hline $2+$ & $2 \quad(0.2)$ & $1 \quad(0.3)$ \\
\hline
\end{tabular}

$O A D=$ oral antidiabetic drug.

no difference in the Alc level when comparing the pre- to postintervention change for patients in the intervention and control groups $(P=0.240)$.

The proportion of patients who initiated insulin therapy postintervention was similar for the intervention and control groups (6.3\% vs. $7.6 \%$, respectively; $P=0.059)$. When patients were stratified according to predefined high-risk selection indicators, there were no statistically significant differences in Act on Threes campaign-related measures between the study groups $(P>0.05$; Figure 3$)$. Diabetes therapy intensification during the 12-month postintervention period was comparable for the study groups, with most patients not having their OAD therapy intensified during the postintervention period (Table 2).

\section{Characteristics and Predictors of Insulin Initiation}

Determinants of insulin initiation were examined in a subgroup of 2,042 patients with available Alc measures in the preand postintervention periods. Of these, 220 (10.8\%) patients initiated insulin during the postintervention period. Compared with patients who did not initiate insulin $(\mathrm{n}=1,822)$, patients who initiated insulin $(\mathrm{n}=220)$ had a higher mean DeyoCharlson Comorbidity Index score (3.46 vs. 2.77; $P<0.001$ ) and a higher prevalence of diabetic nephropathy (11.8\% vs. $5.7 \% ; P<0.001)$ and hypoglycemia $(8.6 \%$ vs. $5.4 \% ; P=0.049)$ during the pre-intervention period. Compared with patients who did not initiate insulin, a higher proportion of patients who initiated insulin were receiving $\geq 3$ OADs $(62.3 \%$ vs.
49.6\%; $P<0.001)$ and treatment with a glucagon-like peptide-1 receptor agonist (GLP-1 RA; 8.2\% vs. 4.5\%; $P=0.015$ ). During the pre-intervention period, patients who initiated insulin had more outpatient visits than those who did not initiate insulin (mean $=11.1$ vs. 9.6 per patient; $P<0.001$ ) and were more likely to have an Alc level of $\geq 9.0 \%$ (38.6\% vs. $17.8 \%$; $P<0.001$ ).

Table 3 summarizes the findings of logistic regression analyses used to examine predictors of insulin initiation in this population. The Act on Threes educational intervention had no impact on insulin initiation in either the unadjusted or adjusted models. Significant predictors of insulin initiation in the final adjusted model were Deyo-Charlson Comorbidity Index score $(P<0.001)$; use of $\geq 3$ OADs $(P=0.050)$; GLP-1 RA use $(P=0.029)$; and Alc of $8.0 \%-8.99 \%(P=0.029)$, 9.0\%9.99\% $(P<0.001)$, and $\geq 10 \%(P<0.001)$. Alc $<7.0 \%$ significantly reduced the likelihood of insulin initiation in the adjusted model $(P<0.001)$.

\section{Discussion}

Act on Threes was a novel study with a rigorous randomized design aimed at prospectively evaluating the effects of a targeted educational program directed to patients with high-risk T2D and their treating physicians. Act on Threes specifically targeted patients with either no Alc evaluations or those with Alc $\geq 8.0 \%$ and, to our knowledge, is the first randomized study of patients with T2D that compared the effects of a targeted educational program between the intervention and control groups in addition to comparing pre- and postintervention results. The main findings of this study were that the Act on Threes intervention, compared with standard care, did not result in any significant differences in the frequency of Alc testing or in the initiation of insulin among high-risk patients with T2D. Also, the Act on Threes intervention did not result in any differences between the intervention and control groups in terms of campaign-related measures. However, in the intervention and control groups, Alc testing was conducted significantly more frequently postintervention compared with pre-intervention.

Although it is difficult to speculate on the reasons for an increase in Alc testing frequency in the control group, there is confidence in our finding of a lack of a between-group effect because no treating physician was involved in the care of intervention and control group patients. Therefore, control group patients would not have been directed to interventionbased measures. We speculate that the absence of an intervention effect was a result of the higher cost of care associated with additional physician visits and Alc testing in a group of Medicare patients assigned to the intervention group. The intervention group, and particularly those on insulin, would be more likely than control patients to experience the Medicare 
"Act on Threes" Paradigm for Treatment Intensification of Type 2 Diabetes in Managed Care:

Results of a Randomized Controlled Study with an Educational Intervention Targeting Improved Glycemic Control

TABLE 3 Predictors of Insulin Initiation Among Patients with at Least 1 A1c Lab Result (N=2,042)

\begin{tabular}{|c|c|c|c|c|}
\hline \multirow[b]{2}{*}{ Characteristic } & \multicolumn{2}{|c|}{ Unadjusted Model } & \multicolumn{2}{|c|}{ Adjusted Model } \\
\hline & OR $(95 \% \mathrm{CI})$ & $P$ Value & OR $(95 \% \mathrm{CI})$ & $P$ Value \\
\hline \multicolumn{5}{|l|}{ Intervention } \\
\hline Control (reference) & 1.00 & & 1.00 & \\
\hline Act on Threes Intervention & $0.86(0.63-1.17)$ & 0.337 & $0.84(0.61-1.16)$ & 0.300 \\
\hline \multicolumn{5}{|l|}{ Age groups } \\
\hline$<65$ years (reference) & 1.00 & & 1.00 & \\
\hline $65-74$ years & $0.86(0.59-1.26)$ & 0.444 & $0.97(0.64-1.46)$ & 0.880 \\
\hline$>75$ years & $0.77(0.50-1.18)$ & 0.225 & $0.81(0.51-1.29)$ & 0.368 \\
\hline \multicolumn{5}{|l|}{ Gender } \\
\hline Male (reference) & 1.00 & & 1.00 & \\
\hline Female & $1.00(0.76-1.33)$ & 0.991 & $0.98(0.73-1.32)$ & 0.891 \\
\hline \multicolumn{5}{|l|}{ U.S. geographic region } \\
\hline Northeast (reference) & 1.00 & & 1.00 & \\
\hline Midwest & $0.31(0.08-1.17)$ & 0.082 & $0.34(0.08-1.47)$ & 0.151 \\
\hline South & $0.61 \quad(0.17-2.13)$ & 0.436 & $0.60(0.15-2.45)$ & 0.482 \\
\hline West & $0.58(0.16-2.14)$ & 0.414 & $0.60(0.14-2.54)$ & 0.486 \\
\hline \multicolumn{5}{|l|}{ Race } \\
\hline White (reference) & 1.00 & & 1.00 & \\
\hline Black & $0.82(0.56-1.20)$ & 0.311 & $0.79(0.52-1.18)$ & 0.245 \\
\hline Hispanic & $0.43(0.15-1.18)$ & 0.101 & $0.36(0.12-1.03)$ & 0.055 \\
\hline Other & $0.59(0.25-1.38)$ & 0.222 & $0.53(0.22-1.29)$ & 0.160 \\
\hline \multicolumn{5}{|l|}{ MAPD plan type } \\
\hline Standard (HMO) (reference) & 1.00 & & 1.00 & \\
\hline Enhanced (PPO) & $0.77(0.55-1.08)$ & 0.134 & $0.97(0.67-1.41)$ & 0.876 \\
\hline Complete (FFS) & $0.65(0.34-1.22)$ & 0.179 & $0.84(0.43-1.66)$ & 0.617 \\
\hline Deyo-Charlson Comorbidity Index score & $1.14(1.08-1.21)$ & $<0.001$ & $1.14(1.06-1.23)$ & $<0.001$ \\
\hline \multicolumn{5}{|l|}{ Comorbidities } \\
\hline Diabetic retinopathy & $1.23(0.72-2.13)$ & 0.451 & $0.90(0.50-1.62)$ & 0.725 \\
\hline Diabetic nephropathy & $2.21(1.41-3.49)$ & 0.001 & $1.61(0.97-2.67)$ & 0.069 \\
\hline Diabetic neuropathy & $1.31(0.97-1.77)$ & 0.082 & $1.61(0.97-2.67)$ & 0.736 \\
\hline Hypertension & $1.22(0.83-1.80)$ & 0.314 & $1.20(0.80-1.81)$ & 0.387 \\
\hline Dyslipidemia & $1.14(0.84-1.57)$ & 0.404 & $0.98(0.70-1.38)$ & 0.894 \\
\hline Hypoglycemia & $1.66(0.99-2.78)$ & 0.052 & $1.44(0.70-1.38)$ & 0.211 \\
\hline \multicolumn{5}{|l|}{ Number of OADs } \\
\hline 0/1 (reference) & 1.00 & & 1.00 & \\
\hline 2 & $1.72(1.06-2.78)$ & 0.028 & $1.18(0.70-1.98)$ & 0.558 \\
\hline$\geq 3$ & $2.35(1.52-3.63)$ & 0.000 & $1.63(0.99-2.67)$ & 0.050 \\
\hline GLP-1 RA use & $1.92(1.13-3.26)$ & 0.016 & $1.91 \quad(1.07-3.41)$ & 0.029 \\
\hline \multicolumn{5}{|l|}{ Health care resource utilization } \\
\hline Outpatient visits & $1.05(1.03-1.07)$ & $<0.001$ & $1.03(1.00-1.06)$ & 0.073 \\
\hline Inpatient visits & $1.08(0.87-1.34)$ & 0.479 & $0.99(0.77-1.27)$ & 0.922 \\
\hline ED visits & $1.11(0.98-1.26)$ & 0.101 & $1.08(0.93-1.27)$ & 0.073 \\
\hline Endocrinologist visits & $1.30(0.77-2.18)$ & 0.321 & $1.12(0.64-1.96)$ & 0.689 \\
\hline Alc & $1.70(1.18-2.43)$ & 0.004 & & \\
\hline $7.0 \%-7.99 \%$ (reference) & 1.00 & & 1.00 & \\
\hline$<7.0 \%$ & $0.30(0.17-0.53)$ & $<0.001$ & $0.36(0.20-0.65)$ & $<0.001$ \\
\hline $8.0 \%-8.99 \%$ & $1.38(0.94-2.01)$ & 0.099 & $1.54(1.04-2.28)$ & 0.029 \\
\hline $9.0 \%-9.99 \%$ & $2.01(1.30-3.11)$ & 0.000 & $2.26(1.43-3.56)$ & $<0.001$ \\
\hline$\geq 10 \%$ & $3.26(2.13-4.99)$ & $<0.001$ & $3.84(2.45-6.01)$ & $<0.001$ \\
\hline
\end{tabular}

Alc=glycated hemoglobin; $C I=$ confidence interval; $E D=$ emergency department; $F F S=$ fee for service; GLP-1 RA=glucagon-like peptide-1 receptor agonist; HMO = health maintenance organization; $M A P D=$ Medicare Advantage Plan $D ; O A D=$ oral antidiabetic drug; $O R=$ odds ratio; $P P O=$ preferred provider organization. 
coverage gap or "donut hole," which would require patient out-of-pocket expenses to fund the increased level of care. The changes seen pre- and postintervention are consistent with other studies reporting the results of educational interventions. A recent study examining the number of patients with diabetes who received retinal screening after a printed, mailed educational intervention was sent to physicians found no effect for intervention. ${ }^{13}$ Another study investigating the impact of point-of-care Alc testing on provider compliance and Alc levels in a primary care setting reported a significant difference in pre- to postintervention Alc levels (mean Alc 6 months pre-intervention: $8.1 \%$; 6 months postintervention: $7.7 \%$ ), but unlike the present study, it did not include a control group. ${ }^{12}$ Indeed, the lack of effect between the intervention and control groups in the present study challenges the validity of other studies that have shown significant changes in diabetes-related outcomes based on pre- to postintervention design..$^{11,12}$ A cluster randomized controlled trial evaluating the effects of peer support on T2D-related outcomes similarly found no impact of the intervention relative to a control group, but unlike the present study, this study did not employ a pre- versus postintervention comparison. ${ }^{14}$

Another possible reason for the lack of intervention effect in the present study relates to resistance encountered from physicians during the educational intervention. A total of 122 calls from providers were received in response to the mailings for reasons that included reporting that a patient was no longer seen in the practice and that the patient/physician pairing listed on the profile was inaccurate (38.5\%); calls were also received to provide updated information on the patient's Alc testing frequency or results and to relay information about a positive change in care $(32.0 \%)$. A few providers also called to request that they not be sent these types of communications and that reading such materials would be "wasting their time," as they did not require help caring for their patients. Although few in number $(n=3 ; 2.5 \%)$, these calls may represent a widely held but unexpressed sentiment that any intervention that distracts physicians from their current focus or approach is unhelpful and time consuming. This resistance, if it is widespread, is of potential concern because it suggests that the delivery of patient-centered care may be a step too far for some physicians; it may also be a contributor to clinical inertia in the case of insulin initiation. Reasons for inertia in the management of T2D previously identified include patients being reluctant to add new medications, especially insulin, to already complex treatment regimens, as well as a lack of familiarity with insulin therapy initiation and failure to intensify on the part of the primary care physician. ${ }^{15,16}$ Yet, there is a need to further investigate the reasons for inertia in insulin initiation among the physician community. Possible resistance from the physician aside, it is important to acknowledge that this study made no attempt to measure patient or physician engagement with the educational materials. Thus, it is possible that the physician participation rate was sufficiently low as to affect the observable outcomes and may better explain the absence of an intervention effect.

The Act on Threes initiative tried to influence insulin initiation in a positive way; however, only a small proportion of patients initiated insulin therapy during this study. This outcome suggests that clinical inertia, in conjunction with patient and/or physician reluctance to initiate insulin treatment, remains a problem in the managed care setting. The findings of this study in relation to the use of an educational intervention emphasize that simply increasing Alc testing frequency does not promote treatment intensification. This highlights the complexity of clinical inertia and shows that multiple approaches may be required to address clinical inertia in the managed care setting. The Alc threshold of $9.0 \%$ seemed to be a much stronger motivator for treatment intensification, with a 2- to almost 4-fold greater likelihood of insulin initiation associated with an Alc of $9.0 \%$ or higher. Other studies have previously reported an association between increasing Alc level and decreasing clinical inertia. ${ }^{17-19}$ Other significant predictors of insulin initiation in the present study were the Deyo-Charlson Comorbidity Index score, which is a proxy for comorbidities, and use of $\geq 3$ OADs or a GLP-1 RA during the pre-intervention period. A potential reason why the use of a GLP-1 RA predicted treatment intensification with insulin may be that such patients are already experienced with injectables and therefore more willing to initiate insulin.

The development and availability of new classes of OADs may further increase the length of time to insulin initiation. In addition to raising the awareness of ADA-recommended Alc testing, an intervention that would increase awareness among physicians and patients regarding the effect on long-term outcomes of an Alc level $>8.0 \%$ and delayed insulin initiation may be better able to overcome some of the inertia and promote insulin initiation at lower Alc thresholds.

\section{Limitations}

The Act on Threes educational intervention included Medicare T2D patients from the Humana administrative claims database only. Therefore, the results may not be representative of, or generalizable to, all patients with T2D. Further, it is not known what other concomitant interventions the patients received that were not related to this study. For example, managed care organizations are focused on improving quality measures and providing other educational initiatives, with such initiatives potentially affecting the pre- and postintervention outcomes in this study. Although it is unlikely that the 2 arms were affected 
unequally, any impact of such initiatives may have "shadowed" the overall effect of the intervention. As already indicated, no efforts were made to measure patient or physician engagement, which may have been inadequate to achieve an intervention effect. Furthermore, although the educational materials conveyed simple messaging of the ADA, no external testing or validation of the materials was conducted to determine their utility for patients and physicians alike. Finally, personalized Alc goals may be more appropriate because they consider factors such as patient age and health status with the aim of balancing the benefits of glycemic control with its possible risks. ${ }^{20}$ In this study, the less aggressive treatment goals may have affected patient and physician responses to educational intervention.

\section{Conclusions}

The Act on Threes study is the first randomized study comparing pre- and postintervention results in an interventional and a control group. Our findings did not demonstrate an overall significant effect for the educational intervention on outcomes of Alc testing and the campaign measures. Importantly, these findings highlight a major drawback of numerous previous studies that used a pre- versus postintervention comparison without a control group. Given the significant postintervention increase in Alc testing observed in the intervention and control groups, our findings indicate the potential of such studies to generate flawed conclusions with the risk of inappropriately influencing the management of diabetes. Indeed, had we relied on a similar study design, we would have mistakenly concluded that the intervention resulted in a significant improvement in the primary outcome of percentage of patients with $\geq 2$ Alc tests per year. As it was, a similar improvement in the control group negated any intervention effect, leaving us to speculate why.

We suggest that future studies are warranted to determine the effect of educational interventions in aligning physicians and their T2D patients with ADA recommendations. The use of pre- versus postintervention comparisons remains a valid method for determining the effect of an intervention and is particularly relevant for database studies. However, such studies should also use a randomized design that incorporates a control group and focus on a broader segment of the patient population in keeping with the possibility that cost restraints associated with the Medicare model detrimentally affect patient care and the ability of educational interventions to achieve desirable outcomes. Further profiling of determinants of insulin intensification may be helpful in designing and targeting appropriate interventions for patients who are likely to benefit most.

\section{Authors}

NELLA BIESZK, PharmD, and WENHUI WEI, PhD, MS, MBA, Medical Affairs, Sanofi US, Bridgewater, New Jersey. SHANNON L. REYNOLDS, MPSH; CRALEN DAVIS, MS; and PRAVIN KAMBLE, RPh, MS, PhD, Comprehensive Health Insights, Louisville, Kentucky. CLAUDIA URIBE, MD, MHA, PhD, Comprehensive Health Insights, Miramar, Florida.

AUTHOR CORRESPONDENCE: Nella Bieszk, PharmD, U.S. Medical Affairs, Sanofi, 55 Corporate Dr., Bridgewater, NJ 08807. Tel.: 519.736.3047; Fax: 908.243.9086;

E-mail:nella.bieszk@sanofi.com.

\section{DISCLOSURES}

This study was funded by Sanofi U.S. Reynolds, Davis, Kamble, and Uribe are employees of Comprehensive Health Insights, which was contracted by Sanofi U.S. to conduct, publish, and present this study. Bieszk and Wei are employees of Sanofi U.S.

Reynolds and Uribe provided expertise and key clinical insights for the study design and methodology, provided interpretations of the data, contributed to the discussion, and reviewed the manuscript. Bieszk and Wei codeveloped the study design, researched data, contributed to discussion, and reviewed the manuscript. Davis and Kamble collected the data, provided study design, clinical insights, statistical and analytic reflections of the data, drafted the study reports, and reviewed the manuscript. All authors had full access to all the data in the study. Reynolds is the guarantor of this work and, as such, takes responsibility for the integrity of the data and the accuracy of the data analysis.

\section{ACKNOWLEDGMENTS}

Writing/editorial support in the preparation of this manuscript, which was funded by Sanofi U.S., was provided by Rosalie Gadiot, PhD, of Excerpta Medica, who wrote the initial draft of the manuscript.

\section{REFERENCES}

1. Stolar MW, Hoogwerf BJ, Gorshow SM, Boyle PJ, Wales DO. Managing type 2 diabetes: going beyond glycemic control. J Manag Care Pharm. 2008;14(5 Suppl B):S2-19. Available at: http://www.jmcp.org/doi/ abs/10.18553/jmcp.2008.14.S5-B.1.

2. Shogbon AO, Levy SB. Intensive glucose control in the management of diabetes mellitus and inpatient hyperglycemia. Am J Health Syst Pharm. 2010;67(10):798-805

3. Hanefeld M. Use of insulin in type 2 diabetes: what we learned from recent clinical trials on the benefits of early insulin initiation. Diabetes Metab. 2014;40:391-99. Available at: http://www.diabet-metabolism.com/ article/S1262-3636(14)00139-6/pdf. Accessed July 18, 2016.

4. Smolen HJ, Murphy DR, Gahn JC, Yu X, Curtis BH. The evaluation of clinical and cost outcomes associated with earlier initiation of insulin in patients with type 2 diabetes mellitus. J Manag Care Spec Pharm. 2014;20(9):968-84. Available at: http://www.jmcp.org/doi/10.18553/ jmcp.2014.20.9.968.

5. Inzucchi SE, Bergenstal RM, Buse JB, et al. Management of hyperglycemia in type 2 diabetes: a patient-centered approach. Diabetes Care. 2012;35(6):1364-79. Available at: http://www.ncbi.nlm.nih.gov/pmc/articles/ PMC3357214/pdf/1364.pdf. Accessed July 18, 2016. 
6. National Committee for Quality Assurance. The state of health care quality 2014. Available at: http://store.ncqa.org/index.php/2014-state-of-healthcare-quality-report.html. Accessed August 1, 2016.

7. American Diabetes Association. Standards of medical care in diabetes2015. Diabetes Care. 2015;38(Suppl 1):S4-93. Available at: http://care.diabetesjournals.org/content/suppl/2014/12/23/38.Supplement_1.DC1/January_ Supplement_Combined_Final.6-99.pdf. Accessed July 18, 2016.

8. Lian J, Liang Y. Diabetes management in the real world and the impact of adherence to guideline recommendations. Curr Med Res Opin. 2014:30(11):2233-40.

9. Brown JB, Nichols GA, Perry A. The burden of treatment failure in type 2 diabetes. Diabetes Care. 2004;27(7):1535-40. Available at: http://care.diabetesjournals.org/content/27/7/1535.full.pdf+html. Accessed July 18, 2016.

10. Ng CJ, Lai PS, Lee YK, Azmi SA, Teo CH. Barriers and facilitators to starting insulin in patients with type 2 diabetes: a systematic review. Int J Clin Pract. 2015;69(10):1050-70. Available at: http://onlinelibrary.wiley.com/ doi/10.1111/ijcp.12691/epdf. Accessed July 18, 2016.

11. Weber V, Bloom F, Pierdon S, Wood C. Employing the electronic health record to improve diabetes care: a multifaceted intervention in an integrated delivery system. J Gen Intern Med. 2008;23(4):379-82. Available at: http:// www.ncbi.nlm.nih.gov/pmc/articles/PMC2359509/pdf/11606_2007_ Article_439.pdf. Accessed July 18, 2016.

12. Egbunike V, Gerard S. The impact of point-of-care AlC testing on provider compliance and AlC levels in a primary setting. Diabetes Educ. 2013;39(1):66-73.

13. Zwarenstein M, Shiller SK, Croxford R, et al. Printed educational messages aimed at family practitioners fail to increase retinal screening among their patients with diabetes: a pragmatic cluster randomized controlled trial [ISRCTN72772651]. Implement Sci. 2014;9:87. Available at: http://www.ncbi. nlm.nih.gov/pmc/articles/PMC4261896/pdf/13012_2013_Article_826.pdf. Accessed July 18, 2016.
14. Smith SM, Paul G, Kelly A, Whitford DL, O'Shea E, O'Dowd T. Peer support for patients with type 2 diabetes: cluster randomised controlled trial. BMJ. 2011;342:d715. Available at: http://www.ncbi.nlm.nih.gov/pmc/articles/ PMC3039437/. Accessed July 18, 2016.

15. Shah BR, Hux JE, Laupacis A, Zinman B, van Walraven C. Clinical inertia in response to inadequate glycemic control: do specialists differ from primary care physicians? Diabetes Care. 2005;28(3):600-06. Available at: http://care.diabetesjournals.org/content/28/3/600.full.pdf+html. Accessed July 18, 2016

16. Bolen SD, Bricker E, Samuels TA, et al. Factors associated with intensification of oral diabetes medications in primary care provider-patient dyads: a cohort study. Diabetes Care. 2009;32(1):25-31. Available at: http://www.ncbi. nlm.nih.gov/pmc/articles/PMC2606824/pdf/25.pdf. Accessed July 18, 2016.

17. McEwen LN, Bilik D, Johnson SL, et al. Predictors and impact of intensification of antihyperglycemic therapy in type 2 diabetes: translating research into action for diabetes (TRIAD). Diabetes Care. 2009;32(6):971-76. Available at: http://www.ncbi.nlm.nih.gov/pmc/articles/PMC2681018/pdf/zdc971.pdf. Accessed July 18, 2016.

18. Balkau B, Bouée S, Avignon A, et al. Type 2 diabetes treatment intensification in general practice in France in 2008-2009: the DIAttitude Study. Diabetes Metab. 2012;38(Suppl 3):S29-35. Available at: http://www.em-consulte.com/showarticlefile/709574/main.pdf. Accessed July 18, 2016.

19. Mata-Cases M, Benito-Badorrey B, Roura-Olmeda P, et al. Clinical inertia in the treatment of hyperglycemia in type 2 diabetes patients in primary care. Curr Med Res Opin. 2013;29(11):1495-502.

20. Inzucchi SE, Bergenstal RM, Buse JB, et al. Management of hyperglycemia in type 2 diabetes, 2015: a patient-centered approach: update to a position statement of the American Diabetes Association and the European Association for the Study of Diabetes. Diabetes Care. 2015;38(1):140-49. Available at: http://care.diabetesjournals.org/content/38/1/140.full.pdf. Accessed July 18, 2016. 
"Act on Threes" Paradigm for Treatment Intensification of Type 2 Diabetes in Managed Care:

Results of a Randomized Controlled Study with an Educational Intervention Targeting Improved Glycemic Control

\section{APPENDIX A Act on Threes Patient Cover Letter}

Brochure to Help You Understand Your Diabetes Care

Dear [Humana Member Name],

Thank you for having a Humana plan.

Our records show you have diabetes, which is a disease that requires a lot of care. We understand that caring for your diabetes isn't always easy.

We've enclosed a brochure to use when discussing your care with your doctor. It's full of helpful information, especially if you don't know your target Alc goal. The brochure explains an "Alc goal."

The more you understand about your diabetes and how to keep it controlled, the fewer problems it may cause.

Please use this brochure to help you talk to your doctor during your next visit. If you have questions please call [xxx-xxx-xxxx].

\section{APPENDIX B Act on Threes Patient Brochure}

Now is the time to ACT ON 3s for my diabetes

- See your doctor for an Alc* test every 3 months until you are at your goal, then at least every 6 months to make sure you stay there.

- Talk to your doctor about your medications every 3 months if your Alc score is not at your goal. Your doctor may need to increase the dose of the medication you are on, or add another medication.

- If you are on 3 or more medications for your diabetes, and your Alc score is not at your goal, then it is time to talk to your doctor about using insulin.

*The Alc test is a special blood test (not like your home blood sugar testing machine) that gives your doctor a good idea of how controlled your blood sugar has been over the last 3 months. For most patients, the goal Alc is $7 \%$. High blood glucose levels can harm your heart, kidneys, feet, and eyes. The sooner your Alc score gets to goal, the less harm your diabetes might cause you. 
"Act on Threes" Paradigm for Treatment Intensification of Type 2 Diabetes in Managed Care:

Results of a Randomized Controlled Study with an Educational Intervention Targeting Improved Glycemic Control

\section{APPENDIX C Act on Threes Provider Cover Letter}

Dear Physician or Health Care Provider,

Our records indicate that you have a patient with diabetes who is considered high risk based on Alc screening frequency, number of non-insulin antihyperglycemic medications and/or Alc test results. In an effort to help support the well-being of your patients, we have enclosed a brochure that includes the latest American Diabetes Association recommendations for management of diabetes, published in April 2012

Also enclosed, please find a profile of the patient (or patients) who have been identified as high risk, including the reason for their high-risk classification. We respectfully request that you consider this data when treating or monitoring escalation, if appropriate for the individual patient. Humana also encourages coordination of care between patients' primary physicians and specialists.

If you have questions about this information, please contact me at [xxx-xxx-xxxx].

Thank you for your continued care of our members.

\section{APPENDIX D Act on Threes Provider Brochure}

Now is the time to ACT ON 3s for diabetes ${ }^{a}$

Follow Alc every 3 months in patients whose therapy has changed or who are not meeting glycemic goals 1,2

Intensify treatment every 3 months if Alc is not at goal ${ }^{2}$

Consider insulin for patients using 3 or more noninsulin glucose-lowering drugs if Alc is not at goal2,3
A reasonable Alc goal for most patients with type 2 diabetes is $<7.0 \%$. More or less stringent goals may be appropriate for some patients. ${ }^{1}$

Insulin is likely to be more effective than most other agents as a third-line therapy, especially when Alc is $\geq 9.0 \% .^{2}$

For patients presenting with Alc $\geq 10.0 \%-12.0 \%$, insulin should be considered from the outset. ${ }^{2}$

a Based on the ADA/EASD 2012 Position Statement for the Management of Type 2 Diabetes and the ADA Standards of Medical Care in Diabetes-2012.1,2

References: 1. American Diabetes Association. Standards of medical care in diabetes-2012 (position statement). Diabetes Care. 2012;35(suppl 1):S11-S63. 2. Inzucchi SE, Bergenstal RM, Buse JB, et al. Management of hyperglycemia in type 2 diabetes: a patient-centered approach. Position statement of the American Diabetes Association (ADA) and the European Association for the Study of Diabetes (EASD) Diabetes Care. 2012;35(6):1364-79. 3. Rodbard HW, Jellinger PS, Davidson JA, et al. Statement by an American Association of Clinical Endocrinologists/American College of Endocrinology consensus panel on type 2 diabetes mellitus: an algorithm for glycemic control. Endocr Pract. 2009;15(6):541-559. 
"Act on Threes" Paradigm for Treatment Intensification of Type 2 Diabetes in Managed Care:

Results of a Randomized Controlled Study with an Educational Intervention Targeting Improved Glycemic Control

APPENDIX E Sample Patient Profile

Patient Profile

Reason for Classification as High Risk Diabetic Patient:

[reason]

\begin{tabular}{|c|c|c|c|}
\hline $\begin{array}{l}\text { Patient Name } \\
\text { [First Name] [Last Name] }\end{array}$ & $\begin{array}{l}\text { Date of Birth } \\
{[\mathrm{mm} / \mathrm{dd} / \mathrm{yy}]}\end{array}$ & \multicolumn{2}{|c|}{$\begin{array}{l}\text { Address } \\
\text { [123 Main St., Anywhere, USA 12345] }\end{array}$} \\
\hline Visits: & $\begin{array}{l}\text { Provider Name } \\
\text { [Provider 1] } \\
\text { [Provider 2] }\end{array}$ & $\begin{array}{l}\text { Provider Type } \\
\text { [Type] } \\
\text { [Type] }\end{array}$ & $\begin{array}{l}\text { Date of Last Visit } \\
{[\mathrm{mm} / \mathrm{dd} / \mathrm{yy}]} \\
{[\mathrm{mm} / \mathrm{dd} / \mathrm{yy}]}\end{array}$ \\
\hline
\end{tabular}

Alc Trends in the Last 12 Months According to Claims and Lab Data:

\begin{tabular}{|c|c|c|c|}
\hline $\begin{array}{l}\text { Alc Test Date } \\
{[\mathrm{mm} / \mathrm{dd} / \mathrm{yy}]}\end{array}$ & $\begin{array}{l}\text { Alc Test Result } \\
{[\mathrm{x} . \mathrm{x} \%]}\end{array}$ & [mm/dd/yy] & [x.x\%] \\
\hline$[\mathrm{mm} / \mathrm{dd} / \mathrm{yy}]$ & {$[\mathrm{x} . \mathrm{x} \%]$} & {$[\mathrm{mm} / \mathrm{dd} / \mathrm{yy}]$} & [x.X\%] \\
\hline$[\mathrm{mm} / \mathrm{dd} / \mathrm{yy}]$ & [x.x\%] & {$[\mathrm{mm} / \mathrm{dd} / \mathrm{yy}]$} & [x.x\%] \\
\hline$[\mathrm{mm} / \mathrm{dd} / \mathrm{yy}]$ & [x.x\%] & {$[\mathrm{mm} / \mathrm{dd} / \mathrm{yy}]$} & [x.X\%] \\
\hline [mm/dd/yy] & [x.x\%] & [mm/dd/yy] & [x.x\%] \\
\hline$[\mathrm{mm} / \mathrm{dd} / \mathrm{yy}]$ & [x.x\%] & {$[\mathrm{mm} / \mathrm{dd} / \mathrm{yy}]$} & [x.X\%] \\
\hline $\mathrm{mm} / \mathrm{dd} / \mathrm{yy}]$ & [x.x\%] & {$[\mathrm{mm} / \mathrm{dd} / \mathrm{yy}]$} & {$[\mathrm{x} . \mathrm{x} \%]$} \\
\hline$[\mathrm{mm} / \mathrm{dd} / \mathrm{yy}]$ & [x.x\%] & {$[\mathrm{mm} / \mathrm{dd} / \mathrm{yy}]$} & [x.x\%] \\
\hline $\mathrm{m} / \mathrm{dd} / \mathrm{yy}]$ & [x.x\%] & [mm/dd/yy] & [x.x\%] \\
\hline $\mathrm{nm} / \mathrm{dd} / \mathrm{yy}]$ & {$[\mathrm{x} . \mathrm{x} \%]$} & {$[\mathrm{mm} / \mathrm{dd} / \mathrm{yy}]$} & [x.x\%] \\
\hline
\end{tabular}

Presence of Diabetes-Related Comorbid Conditions According to Claims Data:

[comorbidity 1] [comorbidity 2] [comorbidity 3] [comorbidity 4]

[comorbidity 5] [comorbidity 6] [comorbidity 7] [comorbidity 8]

Diabetes-Related Emergency Department Visits:

Total Number in Past 12 Months [number]

Dates of Visits [Date 1] [Date 2] [Date 3] [Date 4]

Diabetes-Related Hospitalizations:

Total Number in Past 12 Months [number]

Dates of Visits [Date 1] [Date 2] [Date 3] [Date 4]

Use of Non-Insulin Anti-Hyperglycemic Agents in the Past 12 Months

[Medication 1] [Date] [Date]

[Medication 2] [Date] [Date]

[Medication 3] [Date] [Date]

[Medication 4] [Date] [Date]

[Medication 5] [Date] [Date]

[Medication 6] [Date] [Date]

[Medication 7] [Date] [Date]

[Medication 8] [Date] [Date]

[Medication 9] [Date] [Date]

[Medication 10] [Date] [Date]

Prescribing Physician

[First Name] [Last Name]

[First Name] [Last Name]

[First Name] [Last Name]

[First Name] [Last Name]

[First Name] [Last Name]

[First Name] [Last Name]

[First Name] [Last Name]

[First Name] [Last Name]

[First Name] [Last Name]

[First Name] [Last Name] 